Expression and purification of recombinant proteins. Recombinant GST-tagged XRCC4 was purified from Hi-5 insect cells infected with baculovirus bvUG7-3. Cells were lysed in IP buffer containing $20 \mathrm{mM}$ imidazole. Proteins were bound to Ni-NTA agarose (Qiagen) and eluted with buffer containing $100 \mathrm{mM}$ EDTA. Supernatants were then incubated with glutathione-Sepharose 4B (Pharmacia) which was eluted with buffer containing $10 \mathrm{mM}$ reduced glutathione. Proteins were dialysed overnight at $4{ }^{\circ} \mathrm{C}$ against $50 \mathrm{mM}$ HEPES, $100 \mathrm{mM} \mathrm{KCl}$, pH7.9.

Recombinant Myc-tagged DNA ligase IV was expressed for $24 \mathrm{~h}$ in XR-1 cells by liposome-mediated transfection of the appropriate expression vector $(10 \mu \mathrm{g}$ plasmid per $3 \times 10^{7}$ cells) and co-infection with vaccinia virus vTF7-3 (ref. 27). Yeast-two-hybrid system. Protein interactions were analysed using the yeasttwo-hybrid system as described ${ }^{28-30}$. The Ku70 and Ku86 fusion constructs have been reported ${ }^{8}$.

Received 19 December 1996; accepted 14 May 1997

1. Stamato, T. D., Weinstein, R., Giaccia, A. \& Mackenzie, L. Isolation of cell-cycle dependent gamma-ray sensitive Chinese hamster ovary cell. Somat. Cell Mol. Genet. 9, 165-173 (1983).

2. Li, Z. et al. The XRCC4 gene encodes a novel protein involved in DNA double-strand break repair and V(D)J recombination. Cell 83, 1079-1089 (1996).

3. Taccioli, G. E. et al. Impairment of $\mathrm{V}(\mathrm{D}) \mathrm{J}$ recombination in double-strand break repair mutants. Science 260, 207-210 (1993).

4. Giaccia, A. J., Richardson, E., Denko, N. \& Stamato, T. D. Genetic analysis of the XR-1 mutation in hamster and human hybrids. Somatic Cell Mol. Genet. 15, 71-79 (1989).

5. Wei, Y.-F. et al. Molecular cloning and expression of human cDNAs encoding a novel DNA ligase IV and DNA ligase III, an enzyme active in DNA repair and recombination. Mol. Cell. Biol. 15, $3206-$ 3216 (1995)

6. Wilm, M. et al. Femtomole sequencing of proteins from polyacrylamide gels by nano-electrospray mass spectrometry. Nature 379, 466-469 (1996).

7. Robins, P. \& Lindahl, T. DNA ligase IV from HeLa cell nuclei. J. Biol. Chem. 271, 24257-24261 (1996).

8. Wu, X. \& Lieber, M. R. Protein-protein and protein-DNA interaction regions within the DNA end binding protein Ku70-Ku86. Mol. Cell. Biol. 16, 5186-5193 (1996).

9. Lindahl, T. \& Barnes, D. E. Mammalian DNA ligases. Annu. Rev. Biochem. 61, 251-281 (1992).

10. Gerstein, R. M. \& Lieber, M. R. Extent to which homology can constrain coding exon junctional diversity in V(D)J recombination. Nature 363, 625-627 (1993).

11. Reeves, W. H. \& Sthoeger, Z. M. Molecular cloning of cDNA encoding the $\mathrm{p} 70(\mathrm{Ku})$ lupus autoantigen. J. Biol. Chem. 264, 5047-5052 (1989).

12. Mimori, T. et al. Isolation and characterization of cDNA encoding the $80-\mathrm{kDa}$ subunit protein of the human autoantigen $\mathrm{Ku}(\mathrm{p} 70 / 80)$ recognized by autoantibodies from patients with sclerodermapolymyositis overlap syndrome. Proc. Natl Acad. Sci. USA 87, 1777-1781 (1990).

13. Hartley, K. O. et al. DNA-dependent protein kinase catalytic subunit: A relative of phosphatidylinositol 3-kinase and the ataxia telangiectasia gene product. Cell 82, 849-856 (1995).

14. Kirchgessner, C. U. et al. DNA-dependent kinase (p350) as a candidate gene for the murine SCID defect. Science 267, 1178-1183 (1995).

15. Blunt, T. et al. Defective DNA-dependent protein kinase activity is linked to V(D)J recombination and DNA repair defects associated with the murine scid mutation. Cell 80, 813-823 (1995).

16. Jackson, S. P. \& Jeggo, P. A. DNA double-strand break repair and V(D)J recombination: involvement of DNA-PK. Trends Biochem. Sci. 20, 412-415 (1995).

17. Hsieh, C. L., Arlett, C. F. \& Lieber, M. R. V(D)J recombination in ataxia telangiectasia, Bloom's syndrome, and a DNA ligase I-associated immunodeficiency disorder. J. Biol. Chem. 268, 2010510109 (1993).

18. Petrini, J., Donovan, J. W., Dimare, C. \& Weaver, D. T. Normal V(D)J coding junction formation in DNA ligase I deficiency syndromes. J. Immunol. 152, 176-183 (1994)

19. Kemp, L., Sedgwick, S. \& Jeggo, P. X-ray sensitive mutants of Chinese hamster ovary cells defective in double-strand rejoining. Mut. Res. 132, 189-196 (1984).

20. Chen, J. et al. Mammalian DNA ligase III: molecular cloning, chromsomal localization, and expression in spermatocytes undergoing meiotic recombination. Mol. Cell. Biol. 15, 5412-5422 (1995).

21. Wilson, T. E., Grawunder, U. \& Lieber, M. R. Yeast DNA ligase IV mediates non-homologous DNA end joining. Nature 388, 495-498 (1997).

22. Grawunder, U., Schatz, D. G., Leu, T. M., Rolink, A. \& Melchers, F. The half-life of RAG-1 protein in precursor B cells is increased in the absence of RAG-2 expression. J. Exp. Med. 183, 1731-1737 (1996).

23. Lieber, M. R. et al. The defect in murine severe combined immune deficiency: joining of signal sequences but not coding segments in V(D)J recombination. Cell 55, 7-16 (1988).

24. Gauss, G. \& Lieber, M. R. DEAE-dextran enhances electroporation of mammalian cells. Nucleic Acids Res. 20, 6739-6740 (1992).

25. Miller, R. D. et al. Gene for the catalytic subunit of mouse DNA-PK maps to the scid locus. Proc. Natl Acad. Sci. USA 92, 10792-10795 (1995).

26. Mann, M. \& Wilm, M. Error-tolerant identification of peptides in sequence databases by peptide sequence tags. Analyt. Biochem. 66, 4390-4399 (1994).

27. Fuerst, T. R., Niles, E. G., Studier, F. W. \& Moss, B. Eukaryotic transient expression system based on recombinant vaccinia virus that synthesizes bacteriophage T7 RNA polymerase. Proc. Natl Acad. Sci. USA 83, 8122-8126 (1986)

28. Gyuris, J., Golemis, E., Chertkov, H. \& Brent, R. Cdil, a human G1 and S phase protein phosphatase that associates with Cdk2. Cell 75, 791-803 (1993).

29. Zervos, A., Gyuris, J. \& Brent, R. Mxil, a protein that specifically interacts with Max to bind Myc-Max recognition sites. Cell 72, 223-232 (1993).

30. Guarente, L. Yeast promoters and lacZ fusion designed to study expression of cloned genes in yeast. Meth. Enzymol. 101, 181-191 (1983).

Acknowledgements. U.G. is a postdoctoral fellow of the Boehringer Ingelheim Foundation. T.E.W. is a Howard Hughes Medical Institute physician postdoctoral fellow. This work was supported by grants to M.R.L. M.R.L. is a Leukemia Society of America scholar. We thank C. Hsieh, A. Kalb and M. Yaneva for comments on the manuscript.

Correspondence and requests for materials should be addressed to M.R.L. (e-mail: lieber_m@froggy. hsc.usc.edu).

\section{Yeast DNA ligase IV mediates non-homologous DNA end joining}

\section{Thomas E. Wilson ${ }^{\star} \dagger$, Ulf Grawunder $\dagger \ddagger$ \& Michael R. Lieber $\dagger$}

Washington University School of Medicine, ${ }^{\star}$ Division of Laboratory Medicine, $\dagger$ Division of Molecular Oncology, Department of Pathology, Box 8118, 660 S. Euclid Avenue, St Louis, Missouri 63110, USA

$¥$ Present address: Norris Comprehensive Cancer Center, University of Southern California, Rm 5425, Mailstop 73, 1441 Eastlake Avenue, Los Angeles, California 90033, USA

The discovery of homologues from the yeast Saccharomyces cerevisiae of the human Ku DNA-end-binding proteins (HDF1 and $K U 80$ ) has established that this organism is capable of nonhomologous double-strand end joining (NHEJ) ${ }^{1-5}$, a form of DNA double-strand break repair (DSBR) active in mammalian $V(D) J$ recombination $^{6-8}$. Identification of the DNA ligase that mediates NHEJ in yeast will help elucidate the function of the four mammalian DNA ligases in DSBR, $V(D) J$ recombination and other reactions ${ }^{9,10}$. Here we show that $S$. cerevisiae has two typical DNA ligases, the known DNA ligase I homologue CDC9 (refs 11-14) and the previously unknown DNA ligase IV homologue DNL4. dnl4 mutants are deficient in precise and end-processed NHEJ. DNL4 and HDF1 are epistatic in this regard, with the mutation of each having equivalent effects. $d n 14$ mutants are complemented by overexpression of Dnl4 but not of Cdc9, and deficiency of Dnl4 alone does not impair either cell growth or the Cdc9-mediated responses to ionizing and ultraviolet radiation. Thus, $S$. cerevisiae has two distinct and separate ligation pathways.

We reasoned that yeast might have an unidentified DNA ligase that catalyses NHEJ, the direct rejoining of a double-strand DNA break in a non-homologous 'end-to-end' fashion, because mammalian cells deficient in DNA ligase I can perform $V(D) J$ recombination ${ }^{15,16}$. We therefore screened the completed $S$. cerevisiae genome sequence by computer analysis for the presence of DNA ligases using all known ligases as the query sequences. Two were revealed: $C D C 9$ itself and the open reading frame YOR005c on the right arm of chromosome XV (accession number Z74913; $P<7.6 \times 10^{-19}$ versus $\left.\mathrm{Cdc} 9\right)$. All other potential matches showed a considerably lower score $(P>0.17)$, with no clear presence of the invariant catalytic lysine. Thus, $S$. cerevisiae has two and only two typical ATP-dependent DNA ligases.

Multiple sequence alignment revealed that YOR005c is the yeast homologue of human DNA ligase IV (termed DNL4; Fig. 1), based on clear conservation of the catalytic domain, the reactive site lysine, and the unique carboxy-terminal extension of human DNA ligase IV (ref. 17). The second ATG in the overall human DNA ligase IV open reading frame has been assigned as the start $\operatorname{codon}^{17}$, but there is a meaningful alignment with Dnl4 starting with the first methionine, arguing that this larger open reading frame is used in some if not all mammalian cells.

All ATP-dependent DNA ligases form a covalent ligase-adenylate intermediate as part of the catalytic mechanism ${ }^{10}$. Only DNA ligase IV forms this complex intracellularly in a stable fashion, so that purified protein is adenylated completely with $\left[\alpha-{ }^{32} \mathrm{P}\right]$ ATP in vitro only after removal of bound AMP, for example by incubation with sodium pyrophosphate (pyrophosphorolysis) ${ }^{18}$. Likewise, covalent protein-adenylate complexes formed specifically with an immunoprecipitated glutathione $S$-transferase (GST)-Dnl4 fusion protein with almost 4-fold greater efficiency following preincubation with sodium pyrosphosphate (Fig. 2), demonstrating that Dnl4 bears 
functional as well as structural homology with human DNA ligase IV.

Yeast bearing the $d n l 4 \Delta$ mutation grew at rates comparable to wild type with no visibly apparent phenotypic change, indicating that Dnl4 is not required for the ligation of Okazaki fragments during DNA replication. Further, yeast bearing only this mutation did not show enhanced sensitivity to ultraviolet light (Fig. 3a) or ionizing radiation (Fig. 3b), indicating that Dnl4 is not required for either excision repair or RAD52-dependent homologous recombination, respectively. However, rad52/dnl4 yeast did show an increased sensitivity to ionizing radiation compared with $\mathrm{rad52} /$ DNL4 yeast, to an extent indistinguishable from that of $\mathrm{rad52} / \mathrm{hdf1}$ yeast (that is, Ku-deficient; Fig. 3b). This is attributed to the loss of NHEJ in either $h d f 1$ or $d n l 4$ mutants which is revealed only when the dominant homologous DSBR pathway is disabled by disruption of the RAD52 gene $\mathrm{g}^{3,5,19}$. A rad52/hdf1/dnl4 triple-mutant strain showed no further increase in radiosensitivity beyond the double mutants, demonstrating that Hdfl and Dnl4 proteins operate in the same

\begin{tabular}{|c|c|c|c|}
\hline \multirow[b]{2}{*}{ Strain } & \multirow[b]{2}{*}{ GST-ligase } & \multicolumn{2}{|c|}{ ADE2 locus genotype } \\
\hline & & ade2-101 & ade $2 \Delta: \because T R P 1$ \\
\hline Parent & - & 100 & $36.2 \pm 6.1$ \\
\hline hdf1 & - & $12.3 \pm 3.6$ & $0.7 \pm 0.7$ \\
\hline$d n / 4$ & - & $22.1 \pm 8.8$ & $0.7 \pm 0.2$ \\
\hline$d n / 4$ & Cdc9 & ND & $0.6 \pm 0.5$ \\
\hline$d n / 4$ & Dnl4 & ND & $33.0 \pm 1.5$ \\
\hline rad52 & - & $50.1 \pm 16.4$ & $30.1 \pm 4.7$ \\
\hline
\end{tabular}

Yeast strains with the indicated combination of gene disruption and chromosomal ADE2 genotype were transformed with Bg/ll-digested pES26 and plated to minimal medium lacking uracil and adenine, selecting for precisely joined plasmids. Relative transformation efficiencies (\%) are shown, with the reference strain for all entries being the ade2-101 parent strain, YW104. All data are normalized to parallel transformations with supercoiled plasmid. Results are the mean \pm standard deviation of two independent experiments. Where indicated, the ade2 $\triangle:: T R P 1 / d n / 4$ strain was first transformed with a plasmid expressing a GST-ligase fusion protein from the strong constitutive $A D H 1$ promoter. ND, not determined.
DNA-repair pathway, namely NHEJ. Notably though, $d n l 4$ yeast cells were able to grow at $37^{\circ} \mathrm{C}$, whereas $h d f 1$ yeast were not ${ }^{1-5,19}$, indicating that Hdf1 is involved in at least one DNL4-independent cellular process.

We next modified an assay in which restriction enzyme-linearized plasmids are transformed into yeast and rejoined intracellulary ${ }^{2,3,5}$, specifically by creating breaks in an ADE2 gene carried on URA3selectable plasmids. Plasmid pES26 has a polyterminator inserted into the BglII site of the ADE2 gene. Yeast cells that have been transformed with $B g l \mathrm{II}$-digested pES26 and precisely rejoined the $A D E 2$ coding sequence (with no nucleotide loss or addition) can therefore be selected on adenine-lacking medium, because uncut plasmid and imprecise joins will yield ade2 yeast. In contrast, plasmid pES16 lacks the polyterminator. Transforming BglIIdigested pES16 therefore allows the simple visualization of colonies that have rejoined the plasmid imprecisely, because these appear red (that is, ade2) in a background of white (ADE2) colonies. With both substrates, the plasmid-borne $A D E 2$ gene can also be repaired by

\begin{tabular}{|c|c|c|c|}
\hline Strain & $\begin{array}{c}\text { Relative efficiency of } \\
\text { imprecise joining }\end{array}$ & $\begin{array}{l}\text { Pvull fragment } \\
\text { sizes in } \mathrm{kb}\end{array}$ & $\begin{array}{l}\text { Fraction with } \\
\text { macrodeletion }\end{array}$ \\
\hline Parent & 100 & $3.0(12)$ & $0 / 12$ \\
\hline hdf1 & $36.2 \pm 10.5$ & $\begin{array}{l}2.9,2.6,2.4(3) \\
2.3(2), 2.2(4), 1.7\end{array}$ & $12 / 12\left(P=7.4 \times 10^{-7}\right)$ \\
\hline$d n / 4$ & $16.4 \pm 4.4$ & $\begin{array}{l}2.8,2.4,2.2(6) \\
1.7(2), 1.6,1.4\end{array}$ & $12 / 12\left(P=7.4 \times 10^{-7}\right)$ \\
\hline
\end{tabular}

The ade2 $\triangle::$ TRP1 parent strain YW112 and its derivatives with the indicated disruptions were transformed with $B g / l$-digested pES16 and plated to minimal medium lacking uracil and containing $10 \mu \mathrm{g} \mathrm{ml}^{-1}$ adenine. Relative efficiencies (\%) are calculated relative to YW112, counting onlyade2 (red) colonies as an indication of the rate of imprecise joining. Results are the mean + standard deviation of 3 experiments. Several plasmids were then recovered from ade 2 transformants of each strain and the size of their ADE2-containing PVull parentheses indicate the number of times a given fragment size was observed if greater than one). For reference, the Pvull fragment is $3.0 \mathrm{~kb}$ in pES16. $P$ values (right column) are from Fisher's exact test

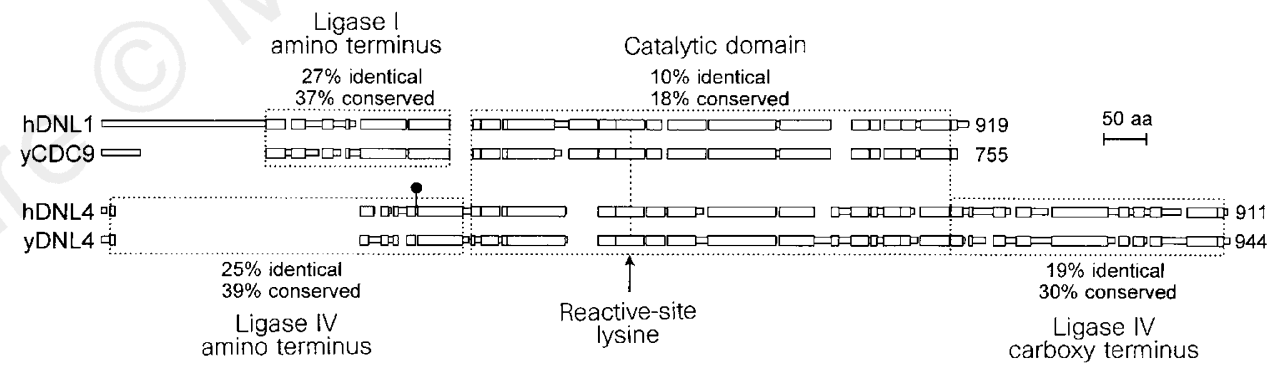

Figure 1 Multiple sequence alignment of human DNA ligase I (hDNL1), yeast CDC9, human DNA ligase IV (hDNL4) and yeast DNL4. Blocks of homology are represented by tall bars, unaligned (dissimilar) regions by short bars, and gaps by blank areas. The position of the conserved reactive-site lysine is indicated by an arrow. Boxes surround the large homologous domains, showing the per cent

amino-acid identity and per cent identity plus highly conservative substitution ('conserved') among all sequences within a given box/domain. The ball on a stick marks the position of the second human DNA ligase IV methionine, originally assigned as the start codon ${ }^{17}$.

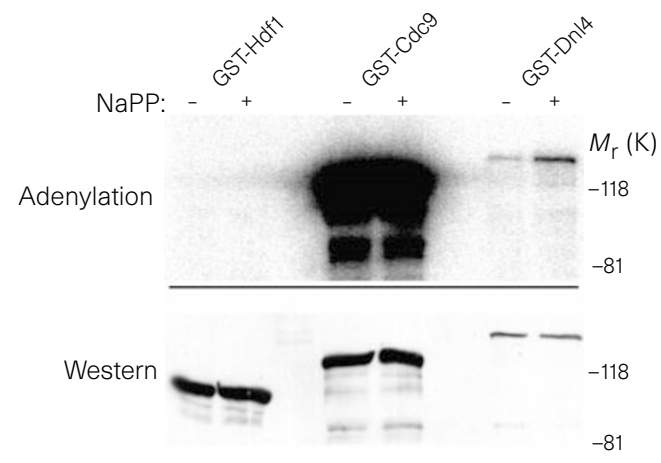

Figure 2 GST-Dnl4 is a pre-adenylated DNA ligase. GST fusion proteins were immunoprecipitated from whole-cell extracts and adenylated with $\left[\alpha^{-32} \mathrm{P}\right]$ ATP. Where indicated, preincubation with sodium pyrophosphate (NaPP) was used to strip preformed ligase-adenylate complexes. Images were generated by Phosphorimager screen exposure (top) and western blotting (bottom) of the same nitrocellulose blot of adenylated proteins. Shorter exposure of the Phosphorimager screen revealed no difference in the extent of adenylation of the two GST-Cdc9 samples. 
recombination with the chromosome, but we can prevent this homologous DSBR event by deleting the chromosomal ADE2 gene.

Table 1 shows the relative efficiency of precise NHEJ among yeasts with a variety of gene disruptions and chromosomal ADE2 genotypes. All results are expressed relative to the parent strain after normalization for the slight variation in overall transformability as assessed by parallel transformations with supercoiled plasmid DNA. Disruption of either HDF1, DNL4 or RAD52 in a parent strain that has the ade2-101 chromosomal mutation (an ochre nonsense mutation) partially reduced the efficiency of transformation, indicating that both homologous DSBR and NHEJ pathways are active in the parent strain. When the ADE2 locus was deleted from the chromosome (ade2 $\triangle:: T R P 1)$, the rate of colony formation decreased in the parent, $h d f 1$ and $d n l 4$ strains, indicating that all are able to perform homologous DSBR of the plasmid only when the chromosomal $A D E 2$ gene is present. Consistent with this, disruption of RAD52 in ade2 $\triangle:: T R P 1$ yeast no longer had any effect. In contrast, disruption of either HDF1 or DNL4 in ade2 $\triangle: T R P 1$ yeast led to a 50 -fold reduction in the rate of colony formation, again showing that both are required for NHEJ. Plasmid expression of GST-Dnl4 restored NHEJ in the $d n l 4$ strain, whereas overexpression of GST-Cdc9 had no effect.

Residual colonies formed by $h d f 1$ yeast harbour plasmids with imprecise rather than precise junctions ${ }^{2,3,5}$. Surprisingly, the ade2 $\triangle:: T R P 1$ parent strain gave colonies with imprecise joins at a

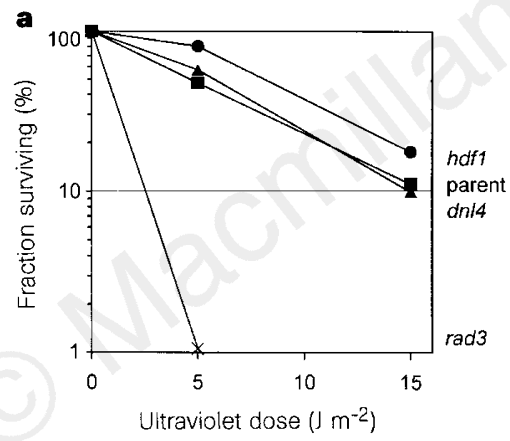

Figure $3 \mathrm{Dn} / 4$ is required for NHEJ but not for excision or homologous DNA repair. $\mathbf{a}$, The YW112 parent strain $(\boldsymbol{\square})$, its derivatives with the hdf1 $(\bullet)$ and $d n / 4(\mathbf{\Delta})$ mutations, and the yeast strain X36B-3C (cross) were plated to YPAD medium and exposed to ultraviolet light at the doses indicated. Colonies were counted after two days at $30^{\circ} \mathrm{C}$ in order to calculate the surviving fraction. The same result was achieved in two independent experiments. X36B-3C is a UV-sensitive control strain (genotype MATa, rad3-2, ade2-1, ade4). b. Haploid yeasts were grown to saturation in YPAD and then irradiated in water with $a^{60} \mathrm{Co}$ source with the total measurable rate, such that $6 \pm 3 \%$ of the total colony yield was ade 2 following transformation with BglII-digested pES16. Moreover, $h d f 1$ and $d n l 4$ disruptants did not show the expected increase in the rate of imprecise joining, but rather a consistent and significant decrease relative to the parent strain (Table 2). However, imprecisely joined plasmids recovered from the parent strain all contained only short insertions and deletions at the joined BglII termini, in essence 'repairing' all but one to a blunt end before ligation (Table 2 and Fig. 4). In contrast, imprecisely joined plasmids recovered from $h d f 1$ or $d n l 4$ yeast all showed large deletions with BglII-digested pES16 ( $\geq 0.1 \mathrm{~kb}$; Table 2), previously described as the "error-prone" pathway ${ }^{3,5}$. We note that two-thirds of plasmids recovered from $h d f 1$ or $d n l 4$ yeast did not have large deletions after double digestion of pES16 with $B g l \mathrm{II} / K p n \mathrm{I}$, but the rate of imprecise joining at these incompatible ends was still reduced 10- to 20-fold compared with the parent strain (data not shown). Thus it was the loss of the dominant precise joining pathway as well as a microdeletion/ insertion end-processing pathway that led to the increased use of the error-prone macrodeletion pathway in $h d f 1$ and $d n l 4$ yeast.

We conclude that Dnl4 is the ligase that normally functions downstream of the Ku proteins Hdfl and Ku80 in both precise and end-processed NHEJ reactions, and that it is neither necessary for (this work) nor sufficient to complement Cdc9-mediated replication, repair and recombination processes ${ }^{11-14}$. Thus, yeast has two functionally separate pathways for DNA ligation. Cdc9 is used in

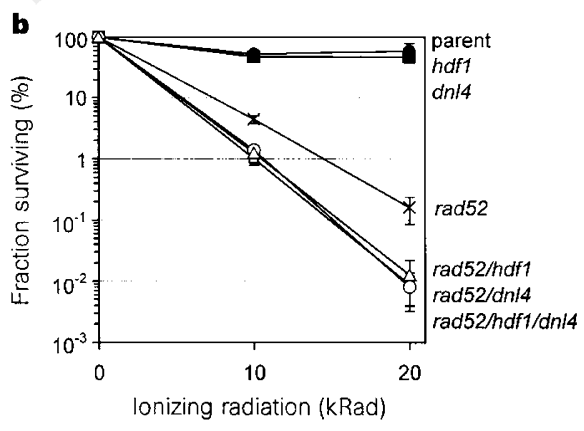

doses indicated. Serial dilutions were plated to YPAD and the colonies counted after 3 days at $30^{\circ} \mathrm{C}$ in order to calculate the surviving fraction. Strains were the YW112 parent $(\mathbf{\square})$, its derivatives with the $h d f 1(\bullet)$ and $d n / 4(\boldsymbol{\Delta})$ mutations, YW130 (rad52, cross), YW132 (rad52/hdf1, $\square$ ), YW136 (rad52/dn/4, O), and YW140 (rad52/ $h d f 1 / d n / 4, \Delta)$. Results are the mean \pm standard deviation of at least two independent experiments for YW112 and its derivatives, and at least three independent experiments for YW130-140.
BgI II

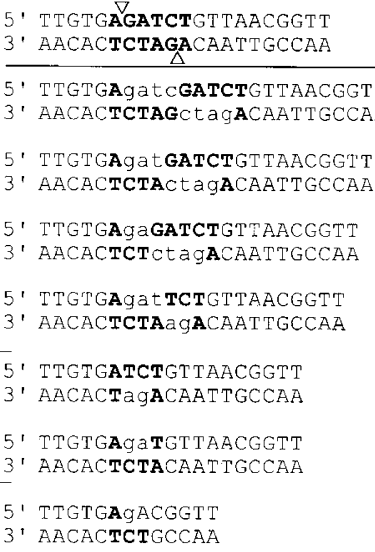

(5)

(1)

(1)

Figure 4 Imprecise NHEJ events in HDF1/DNL4 yeast show microdeletion and end-filling. At the top is the sequence surrounding the Bg/ll site of pES16, with cut sites indicated by triangles. Below are the sequences of imprecisely joined plasmids, as recovered form 12 independentade2 colonies following transformation of YW112 (HDF1/DNL4) with Bg/ll-digested pES16. Nucleotides likely to have been derived from the original plasmid are shown in upper case, with the original $\mathrm{Bg} / \mathrm{ll}$ nucleotides highlighted in bold (note that some have been deleted). De novo nucleotides likely to have been derived from templated polymerization of the Bg/ll $5^{\prime}$ overhangs are shown in lower case. The number of times the sequence was recovered is indicated to the right; the bracket surrounds two joins that are themselves symmetric occurrences of the same joining mechanism. 
processes where the terminal reaction is ligation of a single-stranded nick in double-stranded DNA. In contrast, Dnl4 is used for doublestranded ligation, an activity that by analogy we predict for mammalian DNA ligase IV. In support of this, the accompanying paper $^{20}$ shows that the XRCC4 protein, which causes NHEJ and $V(D) J$ recombination defects when absent, interacts functionally with mammalian DNA ligase IV.

\section{Methods}

Multiple sequence alignment. First, homology blocks were identified with the MACAW program ${ }^{21}$ that aligned all four proteins to clear or probable statistical significance, which resulted in the alignment of most of the catalytic domain. Next, statistically significant blocks of the ligase I and ligase IV human/ yeast homologous pairs were aligned individually, followed when possible by the best logical alignment of the intervening residues. Not all regions of the proteins can be meaningfully aligned.

Yeast strain construction. Except at the loci indicated, all yeast strains used in the plasmid transformation assay are isogenic with the haploid ade2-101 parent strain YW104 (also called YPH499, genotype MATa, ura3-52, trp1 $\Delta-63$, his $3 \Delta-200$, leu $2 \Delta-1$, lys2-801, ade2-101. The ade2 $\Delta:: T R P 1$ variant parent strain, YW112, was derived from YW104 by replacing the entire chromosomal ADE2 sequence with TRP1. Disruptions of HDF1, DNL4 and RAD52 were made in YW104 and YW112 by complete replacement of the relevant coding sequence with the HIS3 gene, followed by PCR verification ${ }^{22}$. Strain designations are as follows. YW118:ade2-101, hdf1 $\Delta:: H I S 3 ;$ YW119:ade2-101,

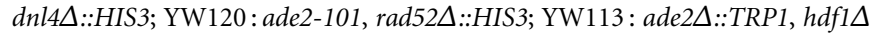
$:: H I S 3 ; \quad$ YW114:ade2 $\Delta:: T R P 1, \quad$ dnl4 $:: H I S 3, \quad$ YW115: ade2 $\Delta:: T R P 1$, rad52 $\Delta:: H I S 3$. The multiply mutated strains used in the radiation-sensitivity experiments were generated by mating and sporulation using YW113, YW114 and CGY2897 (genotype MAT $\alpha$, ura3-52, trp1- $\Delta 63$, lys2- $\Delta 201$, his3- $\Delta 200$, leu2 , ade2, rad1 $\triangle:: A D E 2$, rad52::LEU2). Strain designations are as follows (all strains are additionally $R A D 1$, ura3-52, $\operatorname{trp} 1-\Delta 63$, his3- $\Delta 200$, lys2, leu2, ade2 $\triangle:: T R P 1) . \quad Y W 130: M A T \alpha, \quad r a d 52:: L E U 2 ; \quad Y W 132: M A T \alpha, \quad \operatorname{rad} 52:: L E U 2$, $h d f 1 \Delta:: H I S 3$; YW136:MATa, rad52::LEU2, dnl4 $\Delta:: H I S 3 ;$ YW140:MAT $\alpha$, rad52::LEU2, hdf1 $\triangle:: H I S 3$, dnl4 $\Delta:: H I S 3$. The presence of both the HDF1 and DNL4 deletions in YW140 was verified by PCR of the mutant alleles.

Plasmid construction. GST expression plasmids contained the following PCR-generated fragments in order in the plasmid backbone pRS316 (URA3, CEN/ARS): the $A D H 1$ promoter from plasmid pEG202 (ref. 23); the GST coding sequence from plasmid pGEX-3X (Pharmacia); the CDC9 (pTW268), DNL4 (pTW269) or HDF1 (pTW271) coding sequences; and the $1 \mathrm{~kb} H D F 13^{\prime}$ untranslated sequence. pES16 is pRS316 with a PCR fragment corresponding to the 2.5-kb ADE2 genomic locus inserted at the EcoRI site in the polylinker. pES26 was derived from pES16 by addition of a polyterminator oligonucleotide (with $B g l I I$ ends) into the BglII site of the ADE2 gene.

Immunoprecipitation and adenylation. Yeast cells from 25-ml log-phase cultures were lysed by sonication on ice into $1 \mathrm{ml}$ of IP buffer $(25 \mathrm{mM}$ HEPES/ $\mathrm{KOH}, \mathrm{pH}$ 7.9, $150 \mathrm{mM} \mathrm{KCl}, 10 \mathrm{mM} \mathrm{MgCl}, 1 \mathrm{mM}$ DTT, $0.1 \% \mathrm{NP}-40,1 \mathrm{mM}$ PMSF, $2.5 \mu \mathrm{g} \mathrm{ml}^{-1}$ bestatin, $2 \mu \mathrm{g} \mathrm{ml}^{-1}$ aprotinin, $1 \mu \mathrm{g} \mathrm{ml}^{-1}$ pepstatin $\mathrm{A}$, and $1 \mu \mathrm{g} \mathrm{ml}^{-1}$ leupeptin). Following immunoprecipitation with $40 \mu \mathrm{g}$ GST(B-14) antibody (Santa Cruz), beads were washed with IP buffer, divided into two aliquots, and each preincubated in $1 \mathrm{ml}$ ligase buffer $(60 \mathrm{mM}$ Tris, $\mathrm{pH} 8.0$, $10 \mathrm{mM} \mathrm{MgCl}_{2}, 2 \mathrm{mM} \mathrm{DTT}$, plus protease inhibitors) with or without $0.5 \mathrm{mM}$ sodium pyrophosphate for $5 \mathrm{~min}$ at room temperature. Beads were next washed with ligase buffer, and $30 \mu \mathrm{Ci}$ of $\left[\alpha-{ }^{32} \mathrm{P}\right] \mathrm{ATP}$ mixed with the minimal residual volume for $30 \mathrm{~min}$ at room temperature. After 6\% SDS-PAGE, proteins were transferred to nitrocellulose and a Phosphorimager screen exposure and western blot with the GST(B-14) antibody obtained sequentially from the same membrane.

Plasmid transformation assay. Yeast cells were grown to log phase and transformed with $2-5 \mu \mathrm{g}$ linearized test plasmid by simple lithium acetate transformation without the addition of carrier $\mathrm{DNA}^{24}$. An identical parallel transformation was always done with undigested pES16 or pES26 for the purpose of normalization, so that results for a given strain/digested plasmid combination are expressed as the following ratio of colony counts: [(test strain with digested plasmid)/(test strain with undigested plasmid)]/[(reference strain with digested plasmid)/(reference strain with undigested plasmid)].

Received 19 December 1996; accepted 23 May 1997

1. Feldmann, H. \& Winnacker, E. L. A putative homologue of the human autoantigen $\mathrm{Ku}$ from Saccharomyces cerevisiae. J. Biol. Chem. 268, 12895-12900 (1993).

2. Milne, G. T., Jin, S., Shannon, K. B. \& Weaver, D. T. Mutations in two Ku homologs define a DNA endjoining repair pathway in Saccharomyces cerevisiae. Mol. Cell. Biol. 16, 4189-4198 (1996).

3. Boulton, S. J. \& Jackson, S. P. S. cerevisiae Ku70 potentiates illegitimate DNA double-strand break repair and serves as a barrier to error-prone DNA repair pathways. EMBO J. 15, 5093-5103 (1996).

4. Moore, J. K. \& Haber, J. aE. Cell cycle and genetic requirements of two pathways of nonhomologous end-joining repair of double-strand breaks in S. cerevisiae. Mol. Cell. Biol. 16, 2164-2173 (1996).

5. Boulton, S. \& Jackson, S. Identification of a Saccharomyces cerevisiae Ku80 homologue: roles in DNA double strand break rejoining and in telomeric maintenance. Nucleic Acids Res. 24, 4639-4648 (1996).

6. Lieber, M. R. Immunoglobulin diversity: rearranging by cutting and repairing. Curr. Biol. 6, 134-136 (1996).

7. Weaver, D., Boubnov, N., Wills, Z., Hall, K. \& Staunton, J. V(D)J recombination: double-strand break repair gene products used in the joining mechanism. Ann. N.Y. Acad. Sci. 764, 99-111 (1995).

8. Jeggo, P. A., Taccioli, G. E. \& Jackson, S. P. Ménage à trois: double strand break repair, V(D)J recombination and DNA-PK. Bioessays 17, 949-957 (1995).

9. Lindahl, T. Recognition and processing of damaged DNA. J. Cell. Sci. (suppl.) 19, $73-77$ (1995).

10. Lindahl, T. \& Barnes, D. E. Mammalian DNA ligases. Annu. Rev. Biochem. 61, 251-281 (1992).

11. Wilcox, D. R. \& Prakash, L. Incision and postincision steps of pyrimidine dimer removal in excisiondefective mutants of Saccharomyces cerevisiae. J. Bacteriol. 148, 618-623 (1981).

12. Tomkinson, A. E., Tappe, N. J. \& Friedberg, E. C. DNA ligase I from Saccharomyces cerevisiae: physical and biochemical characterization of the CDC9 gene product. Biochemistry 31, 11762-11771 (1992).

13. Moore, C. W. Ligase-deficient yeast cells exhibit defective DNA rejoining and enhanced gamma ray sensitivity. J. Bacteriol. 150, 1227-1233 (1982).

14. Barker, D. G., White, J. H. \& Johnston, L. H. The nucleotide sequence of the DNA ligase gene (CDC9) from Saccharomyces cerevisiae: a gene which is cell-cycle regulated and induced in response to DNA damage. Nucleic Acids Res. 13, 8323-8337 (1985).

15. Hsieh, C. L., Arlett, C. F. \& Lieber, M. R. V(D)J recombination in ataxia telangiectasia, Bloom's syndrome, and a DNA ligase I-associated immunodeficiency disorder. J. Biol. Chem. 268, 2010520109 (1993).

16. Petrini, J., Donovan, J. W., Dimare, C. \& Weaver, D. T. Normal V(D)J coding junction formation in DNA ligase I deficiency syndromes. J. Immunol. 152, 176-183 (1994).

17. Wei, Y. F. et al. Molecular cloning and expression of human cDNAs encoding a novel DNA ligase IV and DNA ligase III, an enzyme active in DNA repair and recombination. Mol. Cell. Biol. 15, 32063216 (1995).

18. Robins, P. \& Lindahl, T. DNA ligase IV from HeLa cell nuclei. J. Biol. Chem. 271, 24257-24261 (1996).

19. Siede, W., Friedl, A. A., Dianova, I., Eckardt-Schupp, F. \& Friedberg, E. C. The Saccharomyces cerevisiae $\mathrm{Ku}$ autoantigen homologue affects radiosensitivity only in the absence of homologous recombination. Genetics 142, 91-102 (1996).

20. Grawunder, U. et al. Activity of DNA ligase IV stimulated by complex formation with XRCC4 protein in mammalian cells. Nature 388, 492-495 (1997).

21. Schuler, G. D., Altschul, S. F. \& Lipman, D. J. A workbench for multiple alignment construction and analysis. Proteins: Struct. Funct. Genet. 9, 180-190 (1991).

22. Baudin, A., Ozier-Kalogeropoulos, O., Denouel, A., Lacroute, F. \& Cullin, C. A simple and efficient method for direct gene deletion in Saccharomyces cerevisiae. Nucleic Acids Res. 21, 3329-3330 (1993).

23. Gyuris, J., Golemis, E., Chertkov, H. \& Brent, R. Cdil, a human G1 and S phase protein phosphatase that associates with Cdk2. Cell 75, 791-803 (1993).

24. Ito, H., Fukuda, Y., Murata, K. \& Kimura, A. Transformation of intact yeast cells treated with alkali cations. J. Bacteriol. 153, 163-168 (1983).

Acknowledgements. We thank M. Johnston for reagents for yeast-gene disruption, and for helpful discussion on the design of these experiments. T.E.W. is a Howard Hughes Medical Institute physician postdoctoral fellow. This research is supported by NIH grants to M.R.L. M.R.L. is a Leukemia Society of America Scholar.

Correspondence and requests for materials should be addressed to M.R.L. (e-mail: lieber_m@froggy. hsc.usc.edu). 